\section{Breakage of an Endobiliary Metal Stent}

Biliary stenting is the method of choice for achieving palliation of malignant jaundice, metal stents appear to be superior to plastic stents in terms of patency and frequency of dislocation ( $1-3)$, although they are not removable. Complications of metal stent placement are rare, and breakage of the stent has not previously been reported.

A 66-year-old woman with a diagnosis of histologically proved adenocarcinoma of the bile duct found to be unresectable at surgery, received a plastic biliary endoprosthesis for palliation of jaundice. Although the first stent remained patent for seven months, several subsequent stent exchanges became necessary during the following six months, so that insertion of a $9-\mathrm{cm}$ metal stent was decided upon. However, occlusions of this metal stent occurred within two months due to frequent clogging. A 7-Fr percutaneous drain was therefore placed which ended at the proximal stent margin, and the patient was thereafter transferred to our hospital. We introduced the percutaneous drain into the duodenum (Figure 1), and carried out a dilation up to $16 \mathrm{Fr}$, in the usual manner, using Nimura-type bougies, without much resistance being felt during the dilation. At the end of the dilation session, we realized that the stent had broken, and discontinued the procedure (Figure 2). Subsequent cholangioscopy confirmed the rupture, and showed tumor infiltration through the stent mesh. Careful analysis of the radiographs taken prior to the dilation procedures revealed that the guide wire entered the stent from the left side $2 \mathrm{~cm}$ below its proximal margin.

Although we have inserted percutaneous drain and plastic and metal endoprostheses partly through the stent meshes in the past (e.g., to reach the contralateral hepatic duct, with the stents being placed in one of the hepatic ducts), we have never encountered this type of a complication before. After a 16-Fr Yamakawa prosthesis was inserted through the lower part of the stent into the duodenum (Figure 3), the patient's jaundice resolved and, 6 months later, she remained free of complaints.

\section{P. Born. T. Rösch, M. Classen}

Dept. of Medicine II, Klinikum rechts der Isar, Technical

University of Munich, Munich, Germany

\section{References}

1. Wagner HJ, Knyrim K, Vakil N, Klose KJ. Plastic endoprostheses versus metal stents in the palliative treatment of malignant hilar biliary obstruction: a prospective and randomized trial. Endoscopy 1993; 25: 213-8.

2. Davids PHP, Groen AK, Rauws EAJ, Tytgat GNJ, Huibregtse K. Randomised trial of self-expanding metal stents versus polyethylene stents for distal malignant biliary obstruction. Lancet 1992; 340: $1488-92$.

3. Knyrim K, Wagner HJ, Pausch J, Vakil N. A prospective randomized, controlled trial of metal stents for malignant obstruction of the common bile duct. Endoscopy 1993; 25: $207-12$.

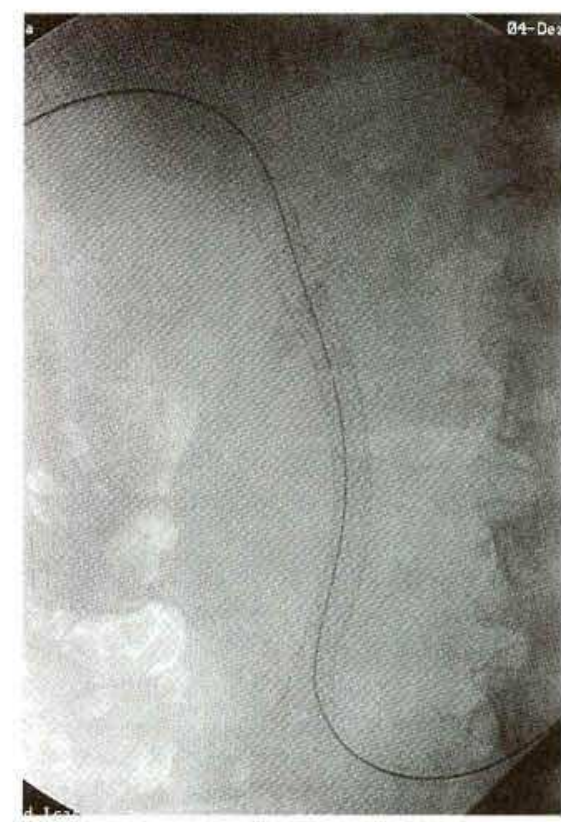

Figure 1: Metal stent in situ; a fracture can be suspected retrospectively (see Figure $\mathbf{2}$.

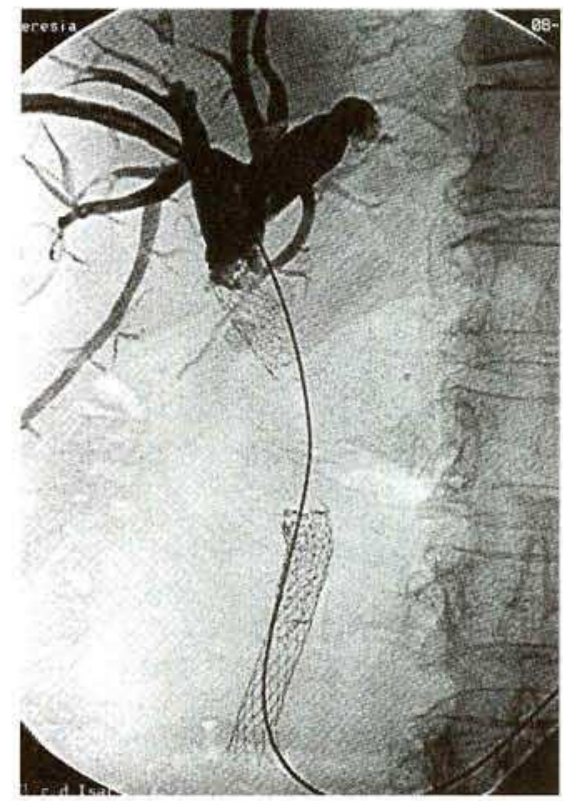

Figure 2: Ruptured metal stent with dislocated stent ends.

Corresponding Author

P. Born, M. D.

II. Medizinische Klinik

Klinikum rechts der Isar

TU Munich

Ismaningerstrasse 22

81675 Munich

Germany

Fax: +49-89-41404905 